\title{
Tumor Necrosis Factor and the Acute Metabolic Response to Tissue Injury in Man
}

\author{
H. Fletcher Starnes, Jr., Robert S. Warren, Malayappa Jeevanandam, Janice L. Gabrilove, William Larchian, \\ Herbert F. Oettgen, and Murray F. Brennan \\ Departments of Surgery and Medicine, Memorial Sloan-Kettering Cancer Center, New York, New York 10021
}

\begin{abstract}
Tumor necrosis factor (cachectin), a protein produced by monocytes and macrophages, has been implicated as an important mediator of the lethal effects of endotoxic shock and the cachexia of chronic infection. Recombinant human tumor necrosis factor $\alpha$ (rTNF) was given intravenously to patients as part of an antineoplastic trial. Fever, tachycardia, and at higher doses, hypotension occurred after a single injection of rTNF. Metabolic effects after rTNF administration were dose related and included enhanced energy expenditure with elevated $\mathrm{CO}_{2}$ production, increased whole body protein metabolism and peripheral amino acid efflux from the forearm, and decreased total arterial amino acid levels associated with a significant increase in plasma cortisol. Elevated serum triglycerides, as well as increased glycerol and free fatty acid turnover were seen, suggesting increased whole body lipolysis and fat utilization after rTNF. These findings indicate that administration of TNF in man reproduces many of the acute physiologic and metabolic responses to tissue injury, including energy substrate mobilization.
\end{abstract}

\section{Introduction}

Profound physiologic and metabolic alterations characteristically follow severe injury and are termed the acute-phase response. These changes represent a transfer of carbon and energy sources from the peripheral tissues muscle and fat to the liver for protein synthesis or to wounds for healing. The acute responses of the body to tissue injury include increased $\mathrm{O}_{2}$ consumption (1), increased whole body protein turnover and peripheral amino acid mobilization (2-4), increased lipolysis and fat utilization $(5,6)$, and increased levels of catecholamines, glucagon, and cortisol (4). Certain of the metabolic responses to tissue injury are simulated by a simultaneous infusion of the three hormones, epinephrine, glucagon, and cortisol (4); however, the full spectrum of the metabolic response to injury cannot be adequately explained by the combined action of these stress hormones. Precise characterization of the mediators of the acute response to tissue injury is unknown.

It has been suggested that the toxic and lethal manifestations of overwhelming infection are mediated by an endogenous host factor, tumor necrosis factor (TNF) ${ }^{1}$ (cachectin) (7,

Address all correspondence to Dr. H. Fletcher Starnes, Jr., Stanford University Medical Center, Room S-067, Stanford, CA 94305-5101. Received for publication 29 March 1988.

1. Abbreviations used in this paper: TNF, tumor necrosis factor, rTNF, recombinant TNF; WBPT, whole body protein turnover.

J. Clin. Invest.

(c) The American Society for Clinical Investigation, Inc. 0021-9738/88/10/1321/05 \$2.00

Volume 82, October 1988, 1321-1325
8). TNF, a monocyte-macrophage-derived polypeptide, was initially described by Old and co-workers (9) to be the agent responsible for the hemorrhagic necrosis in transplanted murine sarcomas after the administration of endotoxin. Subsequently, TNF was shown to have an amino acid sequence homology with cachectin (10), whose effects of decreasing the storage of fat have been suggested to contribute to the pathological state of cachexia associated with severe weight loss (11, 12). A broader role for TNF in mediating the metabolic and physiologic aspects of the acute response to tissue injury is examined by the present study. To investigate the effects of TNF as a mediator of potentially beneficial metabolic alterations in the acute response to tissue injury in man, we studied the metabolic actions of recombinant human TNF $\alpha$ (rTNF) administered to 24 human subjects in an antineoplastic trial.

\section{Methods}

Patients and study design. 24 non-weight-losing adult human subjects (17 male and 7 female ranging in age from 27 to $67 \mathrm{yr}$ with a mean of $51.7 \pm 2.0 \mathrm{yr}$ ) with disseminated cancer were studied in an antineoplastic trial. Patients were placed on metabolically defined diets, with a calorie content of $130 \%$ of their basal energy expenditure (calculated by the Harris-Benedict equation). Each patient received $1.5 \mathrm{~g}$ of protein $/ \mathrm{kg}$ per $\mathrm{d}$, with $30 \%$ of the diet as fat, and the remainder as carbohydrate. At 4:00 p.m. on day 1, a primed constant intravenous infusion of $\left[{ }^{15} \mathrm{~N}\right] \mathrm{glycine}$ was started and urine collection commenced. Patients were kept fasting (except for water) from midnight up until $6 \mathrm{~h}$ after rTNF injection on the first day of treatment (day 2). Between 6:00 and 8:00 a.m. (day 2), patients underwent percutaneous placement of a radial artery catheter and a retrograde antecubital deep basilic vein catheter in the resting, supine position. After subjects had been allowed to rest for $\mathbf{4 5} \mathrm{min}$, arterial and deep vein blood samples were withdrawn for the determination of plasma amino acids and hormones. Simultaneous forearm blood flow was measured using electrocapacitance plethysmography. After this, indirect calorimetry, a primedconstant intravenous infusion of $1-\left[{ }^{14} \mathrm{C}\right] \mathrm{Na}$-palmitate, and a twostaged primed-constant infusion of unlabeled glycerol were performed. A peripheral venous $30-\mathrm{min}$ rTNF infusion $\left(1-300 \mu \mathrm{g} / \mathrm{m}^{2}\right)$ was then started and the glycerol- and palmitate-primed constant intravenous infusions were repeated $2.5-6 \mathrm{~h}$ after rTNF infusion. Indirect calorimetry, arterial and venous amino acid levels, plasma hormone, and substrate samples were collected, and forearm blood flow was measured again at 2.5 and $5 \mathrm{~h}$ after rTNF administration.

rTNF $\alpha$ was supplied by Genentech Inc. (San Francisco, CA) and was more than 99\% pure (as determined by SDS-PAGE analysis), containing $<1.0 \mathrm{ng}$ endotoxin/mg protein as tested by the limulus amebocyte lysate assay. The specific activity was $4 \times 10^{7} \mathrm{U} / \mathrm{mg}$ protein as determined by the $\mathrm{L}$ cell assay with actinomycin $\mathrm{D}$ added. Subjects received intravenous infusions of rTNF over $30 \mathrm{~min}$ at increasing dose levels ranging from 1 to $300 \mu \mathrm{g} / \mathrm{m}^{2}$ after signed, informed consent was obtained. The protocol was approved by the Institutional Review Board at Memorial Sloan-Kettering Cancer Center.

Indirect calorimetry. Expired air was collected in triplicate for 5-min periods into Douglas bags before, and then 2.5 and $5 \mathrm{~h}$ after rTNF administration. Respiratory gas exchange analysis was performed with a medical gas analyzer (1100; Perkin-Elmer Corp., Norwalk, CT). Oxygen consumption and carbon dioxide production were determined. 
Amino acid flux. Arterial and deep vein blood samples were collected for the determination of postabsorptive plasma amino acids before, and 2.5 and $5 \mathrm{~h}$ after the rTNF infusion. Blood samples were immediately centrifuged and stored at $-70^{\circ} \mathrm{C}$. Forearm blood flow was measured simultaneously at these three time points using electrocapacitance plethysmography as described (13). Plasma amino acid flux across the forearm was calculated as the arteriovenous concentration difference times plasma flow at each point in time. Forearm plasma flow was calculated from blood flow by the formula (one minus the hematocrit) (14).

Whole body protein kinetics. Whole body protein turnover (WBPT) was determined both before and acutely after rTNF administration by measuring ${ }^{15} \mathrm{~N}$ enrichment in both urinary urea and ammonia during a primed constant infusion of $\left[{ }^{15} \mathrm{~N}\right]$ glycine according to the method of Picou and Taylor-Roberts (15) as modified and validated by us (16). A priming dose of $2.6 \mathrm{mg}\left[{ }^{15} \mathrm{~N}\right] \mathrm{glycine} / \mathrm{kg}$ was given intravenously and then a continuous infusion of $\left[{ }^{15} \mathrm{~N}\right] \mathrm{glycine}$ at the rate of $2.08 \mathrm{mg} / \mathrm{kg}$ per $\mathrm{d}$ was started and continued for $42 \mathrm{~h}$ with rTNF administration done $19-20 \mathrm{~h}$ after the priming dose of $\left[{ }^{15} \mathrm{~N}\right]$ glycine. Before and during this study all urine was collected as 2-4-h samples, processed, and stored at $-20^{\circ} \mathrm{C}$ until analyzed. Urinary urea and ammonia were isolated and their ${ }^{15} \mathrm{~N}$ enrichments were determined using an isotope ratio mass spectrometer (16). WBPT was determined under steady state conditions, from the isotopic infusion rate and the mean plateau atom percent excess of urinary urea and ammonia. Steady state conditions were achieved within $14 \mathrm{~h}$ both before and after administration of rTNF. Protein synthesis and catabolism rates were calculated from WBPT and nitrogen excretion and intake, respectively (17).

Glycerol and free fatty acid kinetics. Glycerol turnover was calculated from steady state kinetics after a primed-constant two-stage intravenous infusion of unlabeled glycerol given before, and then 3.5-6 h after rTNF infusion using a previously described and validated technique $(5,18)$. Free fatty acid turnover was calculated after a primedconstant intravenous infusion of albumen-bound $1-\left[{ }^{14} \mathrm{C}\right] \mathrm{Na}$-palmitate before, and then $2.5-3.5 \mathrm{~h}$ after the administration of $\operatorname{rTNF}(6,18)$.

Hormone and substrate determination. Plasma amino acid levels were determined by column chromatography on an amino acid analyzer (119CL; Beckman Instruments, Inc., Palo Alto, CA) using lithium citrate buffers with $S$-aminoethylcysteine as an internal standard and ninhydrin as a color-developing agent. Serum triglyceride levels were determined using computerized sequential multiple analysis equipment (Technican Instruments Co., Tarrytown, NY), and plasma lactate levels were measured spectrotometrically using a centrifugal chemical analyzer (Multistat Plus, Instrumentation Laboratories, Lexington, MA). Glycerol concentration in the plasma samples were determined in triplicate using a glycerol kinase enzymatic procedure adapted to a centrifugal chemical analyzer (Multistat Plus, Instrumentation Laboratories). The method of Dole and Meinertz was used to determine plasma free fatty acid concentration (19). The sodium salts of free fatty acids were extracted into an aqueous phase to separate them from other lipids and subsequently counted in a Tricarb liquid scintillation counter (Packard Instrument Co., Inc., Downers Grove, IL). Plasma cortisol and serum insulin (Diagnostic Products, Inc., Los Angeles, CA) and total catecholamines, epinephrine plus norepinephrine (Roche Biomedical Laboratories, Raritan, $\mathrm{NJ}$ ), were determined by standard radioimmunoassay techniques.

Statistics. All data were presented as the mean \pm SEM. Statistical comparisons were made using the paired Student's $t$ test to compare values obtained before and after rTNF infusion. Significance, in all cases, was designated at the level of $5 \%$.

\section{Results}

All patients had dose-related peak elevations in temperature after rTNF administration (Fig. 1) and associated tachycardia. Hypotension (defined as $>25 \%$ decrease in mean blood pres-

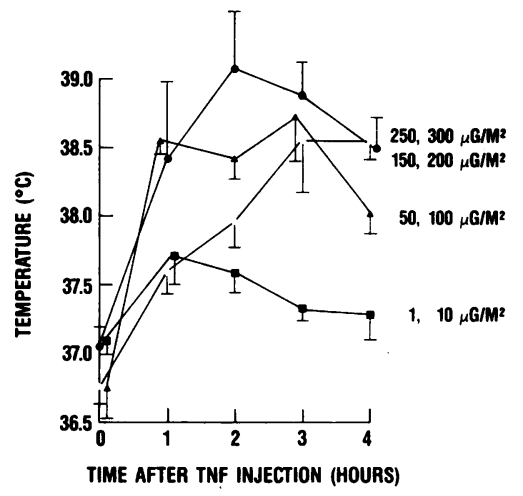

Figure 1. Mean temperature in human subjects with disseminated cancer injected intravenously with rTNF at increasing doses. Temperature obtained by oral thermometers; number of patients in each group was five to seven. Data given as means \pm SE (bars).

sure [systolic blood pressure $+2 \times$ diastolic blood pressure] $/ 3$ ) was observed in 8 out of 24 patients, all at doses $\geq 150 \mu \mathrm{g} / \mathrm{m}^{2}$ of rTNF. Patients with hypotension responded to treatment with intravenous saline infusion except for one patient given $300 \mu \mathrm{g} / \mathrm{m}^{2}$ who developed hypotension that required the use of a vasopressor agent as well as saline infusion.

Significant increases in both oxygen consumption (30\%) and carbon dioxide production (24\%) $2.5 \mathrm{~h}$ after $\geq 100 \mu \mathrm{g} / \mathrm{m}^{2}$ of rTNF were found (Fig. 2), which indicates that these patients became hypermetabolic. There was a significant increase in WBPT (14\%) and whole body protein synthesis (25\%) at rTNF doses of $100 \mu \mathrm{g} / \mathrm{m}^{2}$ or greater (Fig. 3). An elevation in whole body protein catabolism was also seen, although this change did not reach statistical significance. Nitrogen balance either became negative or more negative in 4 of 9 patients after TNF. However, we detected 3-5\% body weight loss after three to four weekly injections of rTNF in only 4 out of 22 patients.

The output of total amino acids from the forearm increased $5 \mathrm{~h}$ after $\mathrm{rTNF}$ injection (Table I). Patients given 10 $\mu \mathrm{g} / \mathrm{m}^{2}$ of rTNF had no significant change in the efflux of the total amino acids from the forearm, while those who received 100 or $200 \mu \mathrm{g} / \mathrm{m}^{2}$ of rTNF showed increasingly more efflux. This was largely due to an increase in the gluconeogenic amino acids alanine and glutamine. At the $200 \mu \mathrm{g} / \mathrm{m}^{2}$ dose of rTNF, the mean forearm blood flow increased $65 \%$ while the efflux of total amino acids from the forearm increased $250 \%$ (Table I).

A decrease in total arterial amino acid concentrations was found $5 \mathrm{~h}$ after rTNF injection, with a greater decrease noted at each higher dose level that went up to a $39 \%$ decrease at 200 $\mu \mathrm{g} / \mathrm{m}^{2}$ of TNF (Table I). Plasma lactate levels increased $50 \%$ from $10.3 \pm 1.4$ to $15.5 \pm 1.6 \mathrm{mg} / \mathrm{dl}$ at $2.5 \mathrm{~h}$ after rTNF at doses of $200 \mu \mathrm{g} / \mathrm{m}^{2}$ in four subjects.

The normally observed diurnal decrease in cortisol levels was preserved at the $10 \mu \mathrm{g} / \mathrm{m}^{2}$ dose of rTNF. In contrast, after the administration of $100-\mu \mathrm{g} / \mathrm{m}^{2}$ doses or even larger ones, a mean increase of $170 \%$ in cortisol levels was noted (Table I), which was comparable to the elevation noted in moderate injury. Levels of insulin were not significantly altered after rTNF (data not shown). A $60 \%$ increase in total plasma catecholamine, from $127 \pm 3$ to $204 \pm 6 \mathrm{pg} / \mathrm{ml}$, was found in four patients $5 \mathrm{~h}$ after $200 \mu \mathrm{g} / \mathrm{m}^{2}$ of rTNF; however, this change did not reach statistical significance.

Serum triglycerides after rTNF increased $28 \%$ from $149 \pm 19$ to $190 \pm 22 \mathrm{mg} \%$ in seven patients at $48 \mathrm{~h}$ after doses of 200 and $250 \mu \mathrm{g} / \mathrm{m}^{2}$ of rTNF $(P<0.01$ by paired Student's $t$ test). We found a $>80 \%$ increase in glycerol turnover in three of four patients studied at doses of 200,250 , and $300 \mu \mathrm{g} / \mathrm{m}^{2}$ of 


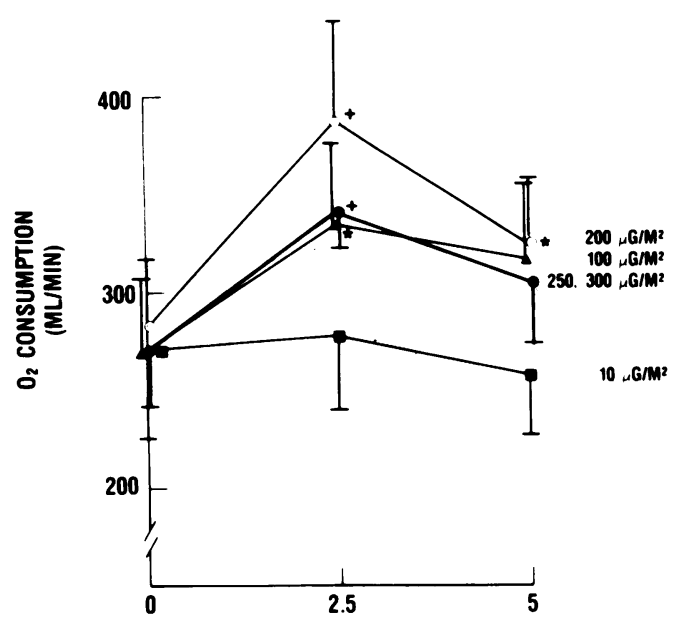

TIME AFTER TNF INJECTION (HOURS)

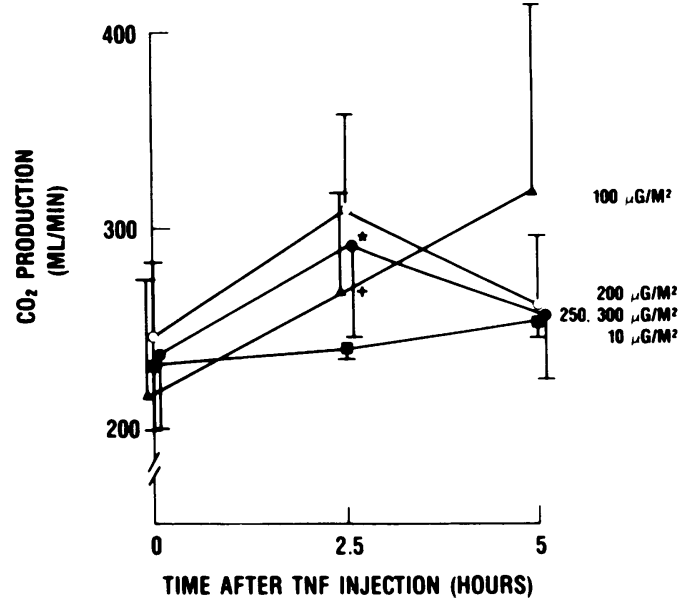

Figure 2. Oxygen consumption and carbon dioxide production determined by indirect calorimetry in patients given rTNF at doses indicated. Data are given as means $\pm \mathrm{SE}$ (bars), with two to four patients in each group. $\left({ }^{*}\right)$ Signifies $P$ $<0.05$ and $(+)$ indicates $P<0.025$ by paired Student's $t$ test, before vs. after TNF.
rTNF. Similarly, there was a $>60 \%$ increase in free fatty acid turnover in three of the four same patients after TNF.

\section{Discussion}

A single injection of rTNF in man resulted in a rapid monophasic, pyrogenic response, associated tachycardia, and hypotension (in 8 of the 24 patients). The increased $\mathrm{O}_{2}$ consumption and $\mathrm{CO}_{2}$ production after TNF suggests that subjects become hypermetabolic acutely after administration of this cytokine. We have shown significant elevations in WBPT and synthesis after TNF. Protein catabolism was found to be increased but not statistically significant. Perhaps greater increases in protein breakdown would be seen after more chronic TNF administration and we are currently investigating this possibility. Other investigators have failed to show an alteration in nitrogen balance after TNF administration (20); however, we have reported an increase in total peripheral amino acid efflux in five subjects after the administration of intravenous TNF, as well as elevations in the acute-phase protein reactant, $\mathrm{C}$-reactive protein $(21)$.

The acute response to tissue injury is typified by a shift from energy storage to energy utilization. One sees accelerated net breakdown of skeletal muscle along with simultaneous shift to anabolic metabolism by the liver (22). The increased flux of total amino acids from the forearm after increasing

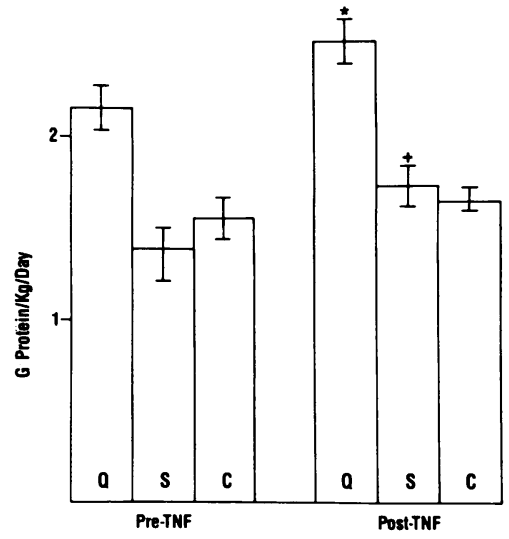

Figure 3. WBPT $(Q)$, whole body protein synthesis $(S)$, and whole body protein catabolism (C) before and acutely after administration of $100-250 \mu \mathrm{g} / \mathrm{m}^{2}$ of rTNF in nine patients. (*) Signifies $P<0.05$ and $(+)$ indicates $P$ $<0.025$ by paired Student's $t$ test, before vs. after TNF. doses of TNF in this investigation can be explained by increased blood flow and unchanged uptake or release of amino acids, or by decreased uptake and increased release of amino acids, or by a combination of all three. The increase measured in forearm blood flow is not sufficient to account for the increase in amino acid efflux. Net amino acid release suggests an increased protein breakdown or a relatively increased breakdown and decreased protein synthesis. The net decreased arterial amino acid concentrations observed after rTNF suggest increased uptake of amino acids by other organs such as the liver, small intestine, or kidney.

The studies of Tracey, Beutler and co-workers have implicated TNF in the lethal effects of endotoxin (7). In one series of experiments, $100 \mu \mathrm{g} / \mathrm{kg}$ of recombinant human cachectin given to dogs resulted in $100 \%$ mortality (23). We have demonstrated pronounced metabolic effects from rTNF given to human subjects at doses of 0.03 to $10 \mu \mathrm{g} / \mathrm{kg}$ (which are equivalent to $1-300 \mu \mathrm{g} / \mathrm{m}^{2}$ ). This raises the possibility of a more physiologic role for TNF at these lower doses. We have noted increased amino acid uptake into the liver in rats given as little as $2.5 \mu \mathrm{g} \mathrm{rTNF} / \mathrm{kg}$ body weight and decreased amino acid uptake into muscle at a $125-\mu \mathrm{g}$ dose of $\mathrm{rTNF} / \mathrm{kg}$ body weight, which suggests a redistribution of amino acids from peripheral skeletal muscle to the liver after TNF administration $(24,25)$. A similar redistribution of amino acids from muscle to liver in rats has been previously demonstrated in the setting of infection with Streptococcus pneumoniae or Salmonella typhimurium (26).

Other authors have noted the effects of TNF/cachectin on lipid metabolism. Cerami and co-workers (27) initially isolated cachectin after investigating why rabbits with trypanosomiasis developed a marked hypertriglyceridemia in the face of body wasting or cachexia. Cachectin was found to decrease transcription of the adipocyte lipoprotein lipase gene in vitro (12). Feingold and Grunfeld (28) demonstrated that TNF also stimulates hepatic lipogenesis in vivo in the rat. Other cytokines have also been shown to induce alterations in lipid metabolism. Hypertriglyceridemia and inhibited post-heparin lipase activity have been seen in cancer patients treated with gamma interferon (29). Our findings of elevated triglyceride levels in patients who received $200 \mu \mathrm{g} / \mathrm{m}^{2}$ or higher doses of rTNF and increased glycerol and free fatty acid turnover after the administration of TNF indicate that TNF injection is associated 
Table I. Acute Alterations of Total Peripheral Plasma Amino Acid Flux, Total Plasma Arterial Amino Acid, Forearm Blood Flow, and Plasma Cortisol after Intravenous rTNF Infusion into Patients

\begin{tabular}{|c|c|c|c|c|c|c|}
\hline rTNF dose & No. & $t^{*}$ & Total amino acid flux & Total arterial amino acid & Forearm blood flow & Cortisol \\
\hline & & & $\mathrm{nmol} / \mathrm{min} 100 \mathrm{cc}$ & $\mathrm{nmol} / \mathrm{ml}$ & $\mathrm{ml} / \mathrm{min} 100 \mathrm{cc}$ & $\mu g / d l$ \\
\hline \multirow[t]{2}{*}{$10 \mu \mathrm{g} / \mathrm{m}^{2}$} & & I & $-666 \pm 65$ & $2424 \pm 66$ & $2.6 \pm 0.2$ & $15.2 \pm 7.4$ \\
\hline & 2 & II & $-815 \pm 68$ & $2030 \pm 154$ & $4.3 \pm 0.1$ & $5.8 \pm 11.5$ \\
\hline \multirow[t]{2}{*}{$100 \mu \mathrm{g} / \mathrm{m}^{2}$} & & I & $-128 \pm 253$ & $2436 \pm 17$ & $4.9 \pm 0.8$ & $15.8 \pm 8.8$ \\
\hline & 3 & II & $-895 \pm 213^{\ddagger}$ & $1627 \pm 141^{\ddagger}$ & $9.0 \pm 2.2$ & $32.4 \pm 5.9$ \\
\hline \multirow[t]{2}{*}{$200 \mu \mathrm{g} / \mathrm{m}^{2}$} & & I & $-530 \pm 208$ & $2528 \pm 113$ & $4.4 \pm 1.3$ & $10.9 \pm 1.4$ \\
\hline & 4 & II & $-1320 \pm 264^{\ddagger}$ & $1550 \pm 76^{\S}$ & $7.3 \pm 0.7$ & $30.0 \pm 2.5^{\S}$ \\
\hline
\end{tabular}

* rTNF was infused into a peripheral intravenous catheter over a 30-min interval at the doses indicated. To compare the physiologic and metabolic responses of patients within each group, blood samples were obtained before infusion (I) and $5 \mathrm{~h}$ after infusion (II). Values are means \pm SE. ${ }^{\ddagger}$ Signifies $P<0.05,{ }^{8}$ indicates $P<0.005$ by paired Student’s $t$ test, I vs. II.

acutely with increased whole body lipolysis and fat utilization, such as that commonly observed in tissue injury $(5,6)$.

It is interesting that rTNF administration was followed by fever in all subjects, but patients failed to become hypermetabolic and failed to develop significant changes in amino acid and protein metabolism or hormonal levels at the lower doses of rTNF $\left(1-10 \mu \mathrm{g} / \mathrm{m}^{2}\right)$. To confirm these observations that energy mobilization occurs after the administration of TNF, independent of temperature elevation, we are currently investigating the ability of indomethacin to abrogate these metabolic changes by blocking the febrile response after TNF administration. Preliminary data indicates that increases in energy and lipid metabolism as well as hormonal changes are seen in patients receiving TNF and gamma interferon who are apyrexial on indomethacin.

After TNF had been given to a subject, a suggestion of increased catecholamine levels was noted at the higher doses of TNF; however, statistically significant elevations were demonstrated only in cortisol levels. We have previously demonstrated elevations in plasma glucagon levels after TNF administration to rats (25), and others have detected elevated catecholamine levels after cachectin is given to dogs (23). It is unlikely that the elevation we detected in cortisol would solely explain the altered amino acid and protein kinetics we have observed after TNF administration; proteolysis and increased total arterial amino acid levels, rather than the decreased levels that we observed after rTNF, are seen after cortisol infusion in human subjects $(30,31)$. We measured IL-1 levels in six patients before, 2.5 , and $5 \mathrm{~h}$ after the administration of 200-250 $\mu \mathrm{g} / \mathrm{m}^{2} \mathrm{rTNF}$, using a bioassay sensitive to $\geq 0.08 \mathrm{U} / \mathrm{ml}$, and found no detectable levels (M. Palladino, personal communication). It is unlikely, therefore, that TNF-induced circulating IL-1 contributes significantly to the acute metabolic alterations that we describe in the present investigation.

A single injection of rTNF in man produces many of the physiologic and metabolic changes seen in the acute response to injury. We have shown that TNF induces increased energy expenditure, increased whole body protein and lipid metabolism, and increased peripheral amino acid efflux when administered to human subjects. The studies of Cerami and coworkers have implicated TNF in the lethal effects of endotoxin $(7,8)$ and have recently shown that an MAb against TNF protects against lethal bacteremia $(32,33)$. In contrast to the pathological effects of TNF in endotoxic shock and in ca- chexia, we have demonstrated potentially beneficial effects of TNF upon energy substrate mobilization in the body's response to tissue injury as an adaptation for survival.

\section{Acknowledgments}

Grateful acknowledgment is extended to Terry Mendes, Lisa Cupit, Martha Uhl, Mark Slattery, Paul Leo, and Tony Tolvo for expert technical assistance. Paul B. Chapman, M.D., Ephraim Casper, M.D., Ann A. Jacubowski, M.D., Al Begas, M.D., Lucy A. Dantis, R.N., Lisa M. Potanovich, R.N., Theresa N. Oleske, R.N., Jan Hackel, R.N., Joan Montagno, R.N., and Nancy Levy, R.N. provided clinical support.

This study was supported in part by National Institute of Health grants T32-CA-09501 for H. F. Starnes and KO8CA-00966 for J. L. Gabrilove.

\section{References}

1. Wilmore, D. W., J. M. Long, A. D. Mason, R. W. Skreen, and B. A. Pruitt. 1974. Catecholamines: mediator of the hypermetabolic response to thermal injury. Ann. Surg. 180:653-669.

2. Birkhahn, R. H., C. L. Long, D. Fitkin, M. Jeevanandam, and W. S. Blakemore. 1981. Whole-body protein metabolism due to trauma in man as estimated by L-[15-N]alanine. Am. J. Physiol. 241:E64-E71.

3. Rosenblatt, S., G. H. A. Clowes, B. C. George, E. Hirsch, and B. Lindberg. 1983. Exchange of amino acids by muscle and liver in sepsis. Arch. Surg. 118:167-175.

4. Bessey, P. Q., J. M. Watters, T. T. Aoki, and D. W. Wilmore. 1984. Combined hormonal infusion simulates the metabolic response to injury. Ann. Surg. 200:264-281.

5. Carpentier, Y. A., M. Jeevanandam, A. P. Robin, J. Nordenstrom, R. E. Burr, R. L. Leibel, J. Hirsch, D. H. Elwyn, and J. M. Kinney. 1984. Measurement of glycerol turnover by infusion of nonisotopic glycerol in normal and injured subjects. Am. J. Physiol. 247:E405-E411.

6. Nordenstrom, J., Y. A. Carpentier, J. Askanazi, A. P. Robin, D. H. Elwyn, T. W. Hensle, J. M. Kinney. 1983. Free fatty acid mobilization and oxidation during total parenteral nutrition in trauma and infection. Ann. Surg. 198:725-735.

7. Tracey, K. J., B. Beutler, S. F. Lowry, J. Merryweather, S. Wolpe, I. Milsark, R. J. Hariri, T. J. Fahey, A. Zentella, J. D. Albert, G. T. Shires, and A. Cerami. 1986. Shock and tissue injury induced by recombinant human cachectin. Science (Wash. DC). 234:470-474.

8. Beutler, B., and A. Cerami. 1986. Cachectin and tumor necrosis factor as two sides of the same biological coin. Nature (Lond.). 320:584-588. 
9. Carswell, E. A., L. J. Old, R. L. Casse, S. Green, N. Fiore, and B. Williamson. 1975. An endotoxin-induced serum factor that causes necrosis of tumors. Proc. Natl. Acad. Sci. USA. 72:3666-3670.

10. Beutler, B., D. Greenwald, J. D. Hulmes, M. Chang, Y. C. E. Pan, J. Mathison, R. Ulevitch, and A. Cerami. 1985. Identity of tumour necrosis factor and the macrophage-secreted factor cachectin. Nature (Lond.). 316:552-554.

11. Pekala, P. H., M. Kawakami, C. W. Angus, M. D. Lane, and A. Cerami. 1983. Selective inhibition of synthesis of enzymes for de novo fatty acid biosynthesis by an endotoxin-induced mediator from exudate cells. Proc. Natl. Acad. Sci. USA. 80:2743-2747.

12. Kawakami, M., P. H. Pekala, M. D. Lane, and A. Cerami. 1982. Lipoprotein lipase suppression in 3T3-L1 cells by an endotoxininduced mediator from exudate cells. Proc. Natl. Acad. Sci. USA. 79:912-916

13. Dresler, C., M. Jeevanandam, and M. F. Brennan. 1987. Extremity blood flow in man: comparison between strain-gauge and capacitance plethysmography. Surgery (St. Louis). 101:35-39.

14. Aoki, T. T., M. F. Brennan, G. F. Fitzpatrick, and D. C. Knight. 1981. Leucine meal increases glutamine and total nitrogen release from forearm muscle. J. Clin. Invest. 68:1522-1528.

15. Picou, D., and T. Taylor-Roberts. 1969. The measurement of total protein synthesis and catabolism and nitrogen turnover in infants in different nutritional states and receiving different amounts of dietary proteins. Clin. Sci. (Lond.). 36:283-296.

16. Jeevanandam, M., M. F. Brennan, G. D. Horowitz, D. R. Rose, M. H. Mihranian, J. Daly, and S. F. Lowry. 1985. Tracer priming in human protein turnover studies with $\left[{ }^{15} \mathrm{~N}\right]$ glycine. Biochem. Med. 34:214-225.

17. Jeevanandam, M., S. F. Lowry, G. D. Horowitz, A. Legaspi, and M. F. Brennan. 1986. Influence of increasing dietary intake on whole body protein kinetics in normal man. Clin. Nutr. (Phila.). 5:41-48.

18. Legaspi, A., M. Jeevanandam, H. F. Starnes, Jr., and M. F. Brennan. 1987. Whole body lipid and energy metabolism in the cancer patient. Metab. Clin. Exp. 36:958-963.

19. Dole, V. P., H. Meniertz. 1960. Microdetermination of long chain fatty acids in plasma and tissues. J. Biol. Chem. 235:2595-2599.

20. Michie, H. F., D. R. Spriggs, J. Rounds, and D. W. Wilmore. 1987. Does cachectin cause cachexia? Surg. Forum. 38:38-40.

21. Warren, R. S., H. F. Starnes, Jr., J. L. Gabrilove, H. F. Oettgen, and M. F. Brennan. 1987. The acute metabolic effects of tumor necrosis factor administration to man. Arch. Surg. 122:1396-1400.
22. Kushner, I. 1982. The phenomenon of the acute phase response. Ann. NY. Acad. Sci. 389:39-48.

23. Tracey, K. T., S. F. Lowry, T. J. Fahey, J. D. Albert, Y. Fong, D. Hesse, B. Beutler, K. R. Manoge, S. Calvano, H. Wei, A. Cerami, and G. T. Shires. 1987. Cachectin/tumor necrosis factor induces lethal shock and stress hormone responses in the dog. Surg. Gynecol. Obstet. 164:415-422.

24. Starnes, H. F., Jr., R. S. Warren, P. S. Conti, S. E. Calvano, and M. F. Brennan. 1987. Redistribution of amino acids in rat liver and muscle induced by tumor necrosis factor requires the adrenal response. Surg. Forum. 18:41-42.

25. Warren, R. S., D. B. Donner, H. F. Starnes, Jr., and M. F. Brennan. 1987. Modulation of endogenous hormone action by recombinant human tumor necrosis factor. Proc. Natl. Acad. Sci. USA. 84:8619-8622.

26. Wannemacher, R. W. 1977. Key role of various individual amino acids in host response to infection. Am. J. Clin. Nutr. 30:12691280.

27. Rouzer, C. A., and A. Cerami. 1980. Hypertriglyceridemia associated with Trypanosoma brucei brucei infection in rabbits: role of defective triglyceride removal. Mol. Biochem. Parasitol. 2:31-38.

28. Feingold, K. R., and C. Grunfeld. 1987. Tumor necrosis factor-alpha stimulates hepatic lipogenesis in the rat in vivo. J. Clin. Invest. 80:184-190.

29. Kurzrock, R., M. F. Rohde, J. R. Quesada, S. H. Gianturco, W. A. Bradley, S. A. Sherwin, and J. U. Gutterman. 1986. Recombinant gamma interferon induces hypertriglyceridemia and inhibits post-heparin lipase activity in cancer patients. J. Exp. Med. 164:1093-1101.

30. Legaspi, A., J. D. Albert, S. E. Calvano, M. F. Brennan, and S. F. Lowry. 1985. Proteolysis of skeletal muscle in response to acute elevation of plasma cortisol in man. Surg. Forum. 36:16-18.

31. P. Simmons, J. M. Miles, J. E. Gerich, and M. W. Haymond. 1984. Increased proteolysis: an effect of increases in plasma cortisol within the physiological range. J. Clin. Invest. 73:412-420.

32. Beutler, B., I. W. Milsark, A. C. Cerami. 1985. Passive immunization against cachectin/tumor necrosis factor protects mice from lethal effect of endotoxin. Science (Wash. DC). 229:869-871.

33. Tracey, K. J., Y. Fong, D. G. Hesse, K. R. Manogue, A. T. Lee, G. C. Kuo, S. F. Lowry, and A. Cerami. 1987. Anti-cachectin/TNF monoclonal antibodies prevent septic shock during lethal bacteraemia. Nature (Lond.). 330:662-664. 